\title{
Investigating the Effect of Cultural Schemata Activation on EFL Learners' Listening Comprehension
}

\author{
Soheil Mahmoudi \\ English Preparatory School, Department of Foreign Languages, Uskudar University, Istanbul, Turkey
}

\section{Email address:}

soheilmahmoudi70@gmail.com

\section{To cite this article:}

Soheil Mahmoudi. Investigating the Effect of Cultural Schemata Activation on EFL Learners' Listening Comprehension. English Language, Literature \& Culture. Vol. 2, No. 6, 2017, pp. 99-104. doi: 10.11648/j.ellc.20170206.12

Received: September 24, 2017; Accepted: October 19, 2017; Published: December 18, 2017

\begin{abstract}
This study tried to find the possible relationship between listeners' cultural schemata and its activation and their performance in EFL listening comprehension. The participants of this study were two groups of 37 Muslim Iranian students. Firstly, the students were divided into two groups of high and low proficiency. Then, they were exposed to two audio files, one about mosques and the other about cathedrals. In one of the classes the recording about the cathedrals was played first, but in the other the order was reversed. The collected data were inputted into the SPSS program. The null hypothesis of the study was whether listening to a culturally unfamiliar topic (cathedrals) can activate low-level learners' schema of the culturally familiar topic (mosques). The hypothesis of the study was accepted implying that an unfamiliar text, even if it is conceptually similar, cannot activate a culturally familiar schema in the low-level students. This study has pedagogical implications for teaching listening comprehension.
\end{abstract}

Keywords: Cultural Schemata, Language Proficiency, Schema Activation, Listening Comprehension

\section{Introduction}

\subsection{Overview}

One of the biggest problems EFL learners deal with is listening comprehension. Due to great cultural differences between English speaking and non-English speaking countries decoding oral input in English is a very demanding task for EFL learners. This is because they usually are not very familiar with the target language culture. In other words, efficient listening comprehension may not happen among low-level EFL learners simply because they do not have the relevant schema. But the question is if their comprehension will improve significantly after their schema is activated with a culturally unfamiliar text.

Schema is an abstract structure of knowledge, a mental representation which remains in memory. The scientific definition of the word schema was first offered by the German Psychologist Bartlett in 1932. The concept was later perfected by the American artificial intelligence expert Rumelhart. Schema is a record of past experiences, and events (Bartlett, 1932). Schema is background knowledge or organized cognition that is generally related to cultural phenomena. It is predictable knowledge which is stored in memory (Zhou, 2002).

Regarding the fact that listening comprehension is a cognitive process, an active schema may help students better comprehend the text they are listening to. Thus, unless students do not activate their prior knowledge when they face new things or things they do not have enough background knowledge about, they will not be able to fully comprehend the text. In other words, passive schema should be activated in order to be influential. Again this has something to do with the learners' level of proficiency.

In successful listening comprehension, listeners should activate their schema and use both of the listening comprehension modes, namely bottom-up and top-down, at the same time. Vandergrift (2004) believes that for fluent listening comprehension, automatic processing of information at both bottom-up and top-down levels is necessary. Researchers, EFL teachers, and curriculum developers have always attempted to find out what the components of listening comprehension are but many of them have come to the conclusion that listening comprehension is an inferential process which needs both bottom-up and top-down processes. Listening 
comprehension, like reading comprehension, is, therefore, an interactive process that involves background knowledge in addition to vocabulary and syntactic knowledge to be accomplished (Al-Shumaimeri's 2006; August et al., 2006; Burgoyne et al., 2013. Mahmoudi \& Mahmoudi, 2017). However, schema theory largely has focused on top-down processes more than the bottom-up mode. What should not be neglected here is the crucial role of the teachers that help learners build new schema and activate their past schemata of different topics.

Investigations on whether topic familiarity and schema activation can override language proficiency in learners with low-proficiency have brought about mixed results. This study tried to take a further step in clarifying these issues.

This study was a non-experimental study but one that tried to explore the effects of schema activation with a culturally unfamiliar text on EFL learners' listening comprehension. The data were collected in just one session by playing the recorded texts. The study involved no intervention.

\subsection{Statement of the Problem and Purpose of the Study}

What makes English excerpts difficult to understand for many EFL learners is that most original English excerpts contain western values with which EFL learners are not familiar. Moreover, learners' cross-cultural schemata are almost never activated before any kind of listening activity.

Due to the fact that listening comprehension performance is extremely important for communication and also students' success at standardized tests such as IELTS and TOEFL, understanding how much cross-cultural schema activation and language proficiency affect listening comprehension seems to be necessary. Of course, studies addressing these issues have already been conducted in different parts of the world, but the findings are mixed with some placing more emphasis on students' proficiency and others on their topic familiarity.

\subsection{Variables of the Study}

There was one independent categorical variable (order of presentation) having two levels and one dependent variable (listening comprehension) in this study. One class was exposed to the familiar text first but the other class was exposed to the unfamiliar text before the familiar one.

\subsection{Research Question and Hypothesis}

The present study tried to answer the following research question:

Does presenting of an unfamiliar but conceptually related text before the familiar one have any positive effect on the low-level students' listening comprehension of the familiar text?

The following null hypothesis was extracted from the research question above.

H0: Presenting an unfamiliar but conceptually related material before the familiar one does not have any positive effect on low-level students' listening comprehension of the familiar text.

\section{Literature Review}

\subsection{Introduction}

Researchers have always sought solutions to the problem of foreign language listening comprehension. Some of them have prescribed syntactic and semantic simplification and many others activities that are believed to enrich vocabulary knowledge. Schema activation is another activity that is given a hoot in the contemporary literature.

\subsection{The Impact of Background Knowledge}

The significant effect of background knowledge on listening comprehension ability has been highlighted by (Bilokcuoglu, 2014). More to the point, Markham and Latham (1987) also concluded that listeners successfully remember passages which are related to their background knowledge. The excerpts they used, in their study, were about the prayer rituals of Islam and Christianity. Participants of that study did best on the excerpts related to their own religion or cultural schema. Therefore, it can be said that background knowledge overrides language proficiency in both listening and reading comprehension (Roller \& Matambo, 1992). Anderson and Lynch (2000) also concluded that successful listening comprehension is bound to efficient schematic knowledge.

\subsection{The Impact of Proficiency on Listening Comprehension}

According to Hudson (1988) and Carrell (1983) background knowledge is not as important as language proficiency in comprehending texts. Low-proficiency students cannot comprehend texts even with background knowledge about that texts Pulido (2004). Pulido (2004) believes that background knowledge can facilitate comprehension just for low- proficiency students.

\subsection{Schema Activation}

In listening teaching and learning, schema is separated to three important parts: linguistic schema, content schema and formal schema. The first one refers to the listener's knowledge of form. Carrell and Eisterhold (1988) believe that linguistic schema is the listener's existing linguistic knowledge, such as, phonetics, grammar, lexis, and so on. In other words, it refers to student's basic knowledge of the language. The second one refers to listener's own knowledge about the world. It depends on their age, culture, and so on. Carrell and Eisterhold (1983, as cited in Bao, 2016) claim that content schema provides people with a foundation, a basis for comprehension. Content schema refers to background knowledge which is related to national and social knowledge. It refers to topic familiarity, previous experiences, and cultural knowledge. The third one refers to rhetorical organization of structures of different types of 
texts. Formal schemata are information about differences among rhetorical structures, such as, differences in genre, differences in fable, etc.

Many researchers endorse that, activating students' existing knowledge enhances their listening comprehension ability. It is necessary for a learner to activate his/her linguistic schema to decode syntax, phoneme, meaning, and pronunciation of the heard text (Bilokcuoglu, 2014). Listening cannot be simplified to hearing only. It is a complex process that involves sensing and attending, understanding and interpreting, remembering, and responding (Goh, 2002, as cited in Bilokcuoglu, 2014). In schemata activation students rely on their prior knowledge about the text and link new information to that background knowledge. Successful activation of background knowledge leads to successful listening comprehension (Mai, et. al., 2014). Schema activation plays a great role in development of the field of cognitive psychology. It involves a lot of cognitive processes such as, differencing, remembering, reasoning, and problem solving. (Alimohamadi \& Poordaryiaenejad, 2015).

Schemata is influenced by the past. In other words, old knowledge influences new information (Alimohamadi \& Poordaryiaenejad, 2015). It is the foundation of cognition (Mai, et al., 2014). In schemata activation students rely on their prior knowledge about the text and link new information to that background knowledge (Mai, et al., 2014). Successful activation of background knowledge leads to successful listening comprehension (Bilokcuoglu, 2014, Mai, et al, 2014). Even though many studies point to the positive influence of schema activation on listening comprehension, some studies show that schema activation does not have such a positive effect (Schmidt-Rinehart, 1994).

Many researchers have also concluded that it is not just insufficient background knowledge that hinders reading and listening comprehension, rather, some learners possessing the background knowledge have been found to be unable to activate their background knowledge (e.g., Carrell, 1983; Ridgway, 1997; Roller, 1990).

Since both reading and listening are receptive skills, findings in EFL reading comprehension can also be applicable to EFL listening comprehension.

There are many studies that support the idea that schema activation facilitates reading and listening comprehension to a great extent (e. g., Graves \& Cook, 1980; Nassaji, 2002). Preexisting schema can be activated and used in many occasions (Nassaji, 2002). Comprehension will simply fail if the needed schema is not activated (Carrell, 1984, as cited in Nassaji, 2002). A good example to explain how schema helps comprehension would be the one given by Nassaji (2002, p. 449), "if in reading a text, a reader encounters a sentence such as "He pounded a nail into the wall," the word "hammer," which is one of the default values associated with the verb "pound," will be simultaneously activated and used to fill in the empty slot for the agent of the verb, leading to the inference that the pounding has been probably done with

\section{a hammer."}

Listening and reading, both are receptive skills and active processes that entail meaning construction beyond simple decoding and understanding. Schema activation clearly helps processing the oral code (Hayati, 2009). Sadighi and Zare (2002) in their study, investigated the effects of background knowledge on listening comprehension. They activated the subjects' schema in their experimental group by giving a treatment and finally concluded that the group whose schema was activated performed better than the control group whose schema was not activated prior to the listening comprehension test.

Familiar terms used in a passage also help listeners a better recall of the information they hear and assists them perform better in listening tests. Familiar terms, thus, can activate listeners' schema (Alptekin, 1981). Buck (1995) suggests a list of preparatory activities including, pre-teaching vocabulary and sentence structures, previewing questions, pre-listening to relevant topics, pre-discussing relevant topics, etc., for schema activation. The above-mentioned preparatory activities help EFL listeners link their existing knowledge with the new information embedded in the listening excerpt, hence, activating their schema (Mendelsohn, 1995).

Students should have related schema in their mind and they should activate them before listening. Goh (2002) suggests the following techniques to activate stored schemata: brainstorming, mind-mapping, discussion, games, guide-questions, pictures, predictions, elimination, and skimming.

\subsection{Anxiety}

Another aspect which affects listening comprehension is anxiety. It is a proven fact that extreme anxiety has a debilitating effect. In fact, one of the barriers to successful EFL listening comprehension performance is test anxiety. Test anxiety leads students to experience a stressful situation in which they cannot demonstrate their real ability in EFL listening comprehension (Messick, 1996). Motivation plays a great role in learning listening skill (Brown, 2000). Even though motivation is a mentally different construct, high levels of motivation alleviates the negative effects of anxiety.

\section{Method}

\subsection{Introduction}

This study tried to find out if schema creation of a culturally unfamiliar but conceptually related material in the target language can help low-level students understand culturally familiar material better. The students were exposed to two recorded listening files one about mosques and the other about cathedrals. In one of the classes the recording about mosques was played first and the recording about cathedrals second. In the other class the order was reversed. This reversal of ordering was to measure the possible influence of creating new schema on the participants' 
listening comprehension of the familiar text which was conceptually related to the unfamiliar one. The students' listening comprehension scores were obtained by giving ten questions to them to answer at the end of each treatment session. The collected data then were analyzed using SPSS.

\subsection{Participants}

The participants of this study were all Muslim Iranian EFL learners and had firsthand experience of mosques as Muslims living in an Islamic state. All of the participants had one year of English language learning experience at least. They were teenagers between 13 and 16 years old. The proportions of male and female students were almost the same with twenty students in each class. Since, three of the respondents had answered none of the questions, they were excluded from the study. Therefore, the final number of the students stood at 37. The participants' mother tongue was Azeri Turkish but they were all quite fluent in Persian as well.

The participants in the classes were given a proficiency test (OPT), which lacks the listening section, and were divided into two groups of low-proficiency and highproficiency based on their performance on this test. Giving a listening test would not serve the purposes of the study because it was not necessary to have homogeneous classes.

\subsection{Instruments}

There were three types of instruments in this study. The first instrument was the Oxford Placement Test or OPT. The other instrument included two listening comprehension audio files, one about Mosques and the other about Cathedrals. The answer sheets constituted the last instrument.

\subsection{Design of the Study}

The design of this study was quasi-experimental since although the independent variable of the study was not manipulated, it was activated. No treatment, no control group, and no random assignment were involved but the students in the two classes were divided into two groups of low ability and high ability depending on their scores on Oxford Placement Test (OPT). OPT does not measure students' listening ability but it was thought that measures of reading, vocabulary, and grammar knowledge can be generalized to the learners' listening ability.

\subsection{Procedure}

OPT, was administered not to determine the language proficiency of the participants, because they were put in intermediate classes by the institutional officials, but to divide the students in each class to the two groups of high and low proficiency within the lower and upper limits of the intermediate level. After deciding about the students' proficiency levels, they were exposed to two audio files which were prepared about two topics one culturally familiar to them and the other culturally unfamiliar. The first and the second audio files both were retrieved from a website offering different levels of English texts for learners along with a number of questions following each of them to check the users' comprehension. These texts had been piloted and it was assured that intermediate students could understand their contents. The played recordings in the classes were prepared by having the Adobe reader program's Read Out Loud facility. After retrieving the texts from the site, the difficulty of each text was measured using the Flesch Reading Ease Test. In this scale a larger number points to an easier text. The texts were similar in terms of their difficulty (between 60-70) and appropriate for the participants' level. The total number of questions following each text was 8 each having the value of one point. The students in both classes listened to these two texts and then answered the listening comprehension questions that followed.

\section{Data Analysis}

The research hypothesis stated that presenting an unfamiliar but conceptually related text before the familiar one does not have any positive affect on low-level students' listening comprehension of the familiar text. To test this hypothesis, we needed to compare low-proficiency students' performance on a familiar topic before being exposed to a conceptually similar but culturally unfamiliar topic with their performance on the same familiar topic after being exposed to a conceptually similar but culturally unfamiliar topic. This was possible because about half of our low-level students were exposed to the unfamiliar topic and the other half to the familiar one first. If no significant difference were located, it would mean that the presentation or non-presentation of conceptually similar but culturally different material does not make any difference to low-level students' listening comprehension and therefore the hypothesis would be accepted. But, if a significant difference was found, it would imply that schema creation with conceptually similar but culturally unfamiliar content might be helpful to the students' listening comprehension.

Since the low-proficiency students were divided into two groups (half of the students in one class and the other half in the other class), we could use the Mann-Whitney U test. Table representing the results of this test and the following Ranks table are given below. As can be seen, neither the difference value in the Mann-Whitney $U$ table is significant nor the mean ranks are different.

Table 1. Mann-Whitney U Test Results.

\begin{tabular}{|c|c|c|c|c|}
\hline & & \multicolumn{3}{|c|}{ Level } \\
\hline \multicolumn{3}{|c|}{ Mann-Whitney U } & \multicolumn{2}{|l|}{40.000} \\
\hline \multicolumn{3}{|c|}{ Wilcoxon W } & \multicolumn{2}{|l|}{95.000} \\
\hline \multicolumn{3}{|l|}{ Z } & \multicolumn{2}{|l|}{.000} \\
\hline \multicolumn{3}{|c|}{ Asymp. Sig. (2-tailed) } & \multicolumn{2}{|l|}{1.000} \\
\hline \multicolumn{3}{|c|}{ Exact Sig. [2*(1-tailed Sig.)] } & \multicolumn{2}{|l|}{$1.000^{\mathrm{b}}$} \\
\hline \multicolumn{5}{|c|}{ Ranks } \\
\hline & order of listening & $\mathbf{N}$ & Mean Rank & Sum of Ranks \\
\hline \multirow{3}{*}{ level } & familiar first & 8 & 9.50 & 76.00 \\
\hline & Unfamiliar & 10 & 9.50 & 95.00 \\
\hline & Total & 18 & & \\
\hline
\end{tabular}


The lack of no difference meant that the presentation of a conceptually similar but culturally different text to the students prior to the familiar one did not make any difference in their listening comprehension. This finding suggests that listening to culturally unfamiliar texts has little, if any, effect on schema activation of the low-level students.

\section{Discussion}

This study revealed that, presenting an unfamiliar but conceptually related text before the familiar one does not have any significant effect on low-level students' listening comprehension of a familiar text. The finding shows that learners' background knowledge will not be activated effectively and they will not be able to better predict what the text is about to link the new information with the previous one. This finding goes against Vandergrift's (2004) assertion that the top-down process plays a greater role in understanding new things at least when it comes to low-level students. The finding confirms Bilokcuoglu's (2014) finding that successful listening will occur when listeners can associate the new listening texts with prior knowledge in their mind in the sense that low-level students are incapable of creating such associations. Following what was said, this study accepts the null hypothesis and claims that presenting unfamiliar but conceptually related materials before the familiar ones does not have any positive effect on low-level students' listening comprehension of the familiar materials.

\section{Conclusion}

This research hypothesized that activating background knowledge before listening is one of the important factors in successful listening comprehension skill. It was thought that by giving a conceptually familiar but culturally unfamiliar text the low-level participants' background knowledge about the familiar topic will be activated and by linking new information to the previous one they will be able to guess answers to some the questions and perform better in their listening comprehension. But, it was proven that familiar schemata is not activated effectively if the listeners do not have enough language proficiency especially if the activating text is unfamiliar. So, to perform at an acceptable level in listening comprehension a reliable level of language proficiency should be developed first. Linguistic ability can even compensate for the insufficient background knowledge though at higher levels lack of background knowledge may lead to occasional misunderstanding. It is after developing the threshold level of language ability that teachers, according to Bilokcuoglu (2014) should help students to build up new background knowledge and help them activate their existing background knowledge. Markham and Latham (1987), too, conclude that schema activation influences listening comprehension but as was just mentioned this can be envisioned only after learners have mastered language to an acceptable degree.

\section{Implication of the Study}

This study may have a say in EFL listening comprehension issues. Program writers, curriculum developers, and teachers can use the finding of this research for screening listening materials for their appropriateness for low-level students. They may provide simple and touchable audios for low-level students preferably audios that are accessible to them both in terms of content and language. This study implies that if we are ever going to activate low-level students' schemata, the activating materials should preferably be familiar because unknown materials are inaccessible to low-level learners. By playing a familiar audio, learners will think about the topic, make some conjectures, predict some points, and get ready for the main audio.

Teachers should help students to connect new information to the previous one by various strategies and techniques. Sometimes, they should help students build new schema or background knowledge around a special topic but all these efforts will be useless learners' differing linguistic abilities are taken into account. This study, for example, revealed that if the learners are not linguistically ready, they won't benefit at least from some schema activation strategies.

Another factor is language proficiency of the listeners. High level listeners can understand even new topics or audios, because of their linguistic knowledge, including vocabulary knowledge and knowledge of form. It means that at high-levels, listeners do not waste their time by activating background knowledge. They can understand even unfamiliar audios or texts because of their high level proficiency.

\section{References}

[1] Alimohamadi, F., \& Poordaryiaenejad, A. (2015). Incorporating schema in the improvement of Iranian EFL learners' L2 speaking ability. Journal of Applied Linguistics and Language Research, 2 (8), 100-110.

[2] Alptekin, C. (1981). Socio-psychological and pedagogic considerations in L2 acquisition. TESOL Quarterly, 15 (3), $275-284$.

[3] Al-Shumaimeri, Y. A. N. (2006). The effects of content familiarity and language ability on reading comprehension performance of low- and high-ability Saudi tertiary students studying English as a foreign language. Journal of King Saud University, 18 (2), 1-19.

[4] Anderson, A., \& Lynch, T. (2000). Listening. Oxford: Oxford University Press.

[5] August, D., Francis, D. J., Hsu, H. Y. A., \& Snow, C. E. (2006). Assessing reading comprehension in bilinguals. The Elementary School Journal, 107 (2), 221-238.

[6] Bao, X. (2016). A study on schema theory-based listening teaching mode for English majors. International Journal of English Linguistics, 6 (4), 207-212.

[7] Bartlett, F. C. (1932). Remembering. Cambridge: Cambridge University Press. 
[8] Bilokcuoglu, H. (2014). A schematic approach to teaching listening comprehension. ELU Journal of Sciences.

[9] Brown, H. D. (2000). Principles of language learning and teaching. New York: Longman.

[10] Buck, G. (1995). How to become a good listening teacher. In D. J. Mendelsohn \& G. Rubin (Eds.), A guide for the teaching of second language listening (pp. 113-131). San Diego, CA: Dominie Press.

[11] Burgoyne, K., Whiteley, H. E., \& Hutchinson, J. M. (2013). The role of background knowledge in text comprehension for children learning English as an additional language. Journal of Research in Reading, 36 (2), 132-148.

[12] Carrell, P. L. (1983). Three components of background knowledge in reading comprehension. Language Learning, $33,183-207$.

[13] Carrell, P. L., \& Eisterhold, J. C. (1988). Schema theory and ESL reading pedagogy. In Carrell, P. L., P. L., Devine, J., \& Eskey, D. E. (Ed.). Interactive approaches to second language reading. Cambridge: Cambridge University Press.

[14] Goh, C. (2002). Exploring listening comprehension tactics and their interaction patterns. System, 30, 185-206.

[15] Graves, M., \& Cook, C. (1980). Effects of previewing difficult short stories for high school students. Research on Reading in Secondary Schools, 6, 38-54.

[16] Hayati, A. M. (2009). The impact of cultural knowledge on listening comprehension of EFL learners. English Language Teaching, 2 (3), 144-151.

[17] Hudson, T. (1988). The effects of induced schemata on the Short Circuit in L2 reading. Non-decoding factors in L2 reading performance. In P. L. Carrell, J. Devine \& D. E. Eskey (Eds.), Interactive approaches to second language reading (2nd ed.) (pp. 183-205). New York, NY: Cambridge University Press.

[18] Mahmoudi, S., \& Mahmoudi, A. (2017). Can topic familiarity override language proficiency in reading comprehension? Journal of Language Teaching and Research, 8 (3), 496-506.

[19] Mai, L. H, Ngoc, L. T. B, \& Thao, V. T, (2014). Enhancing listening performance through schema construction activities. Journal of Language Teaching and Research, 5 (5), 1042 1051.
[20] Markham, P. L., \& Latham, M. (1987). The influence of religion-specific background knowledge on listening comprehension of adult second language students. Language Learning, 37, 157-170.

[21] Mendelsohn, D. (1995). Applying learning strategies in the second/foreign language listening comprehension lesson. In D. J. Mendelsohn \& J. Rubin (Eds.). A guide for the teaching of second language listening (pp. 132-150). San Diego, CA: Dominie Press.

[22] Messick, S. (1996). Validity and washback in language testing. Language Testing, 13, 241-256.

[23] Nassaji, H. (2002). Schema theory and knowledge-based processes in second language reading comprehension: A need for alternative perspectives. Language Learning, 52 (2), 439 481.

[24] Pulido, D. (2004). The effects of cultural familiarity on incidental vocabulary acquisition through reading. The Reading Matrix, 4 (2), 20-53.

[25] Ridgway, T. (1997). Threshold of the background knowledge effect in foreign language reading. Reading in a Foreign Language, 11(1), 151-167.

[26] Roller, C. M. (1990). The interaction between knowledge and structure variables in the processing of expository prose. Reading Research Quarterly, 25 (2), 79-89.

[27] Roller, C. M., \& Matambo, A. R. (1992). Bilingual readers' use of background knowledge in learning from text. TESOL Quarterly, 26 (1), 129-141.

[28] Sadighi, F., \& Zare, S. (2002). Is listening comprehension influenced by the background knowledge of the learners? A case study of Iranian EFL learners. The Linguistics Journal, 1(3), 110-126.

[29] Schmidt-Rinehart, B. C. (1994). The effect of topic familiarity on second language listening comprehension. Modern Language Journal, 78 (2), 179-189.

[30] Vandergrift, L. (2004). Listening to learn or learning to listen? Annual Review of Applied Linguistics, 24, 3-25.

[31] Zhou, X. L. (2002). Application of schema theory in listening teaching. Foreign Language and Foreign Language Teaching, 2, 27-30. 